\title{
Multi-Motor Common DC Bus Energy Feedback Grip Based on Super Capacitor Energy Storage Application Research
}

\author{
Yao Chen,Xia Chen,Yulin Xu,Yue Xu,and Zheng Wang \\ ShanDong University Of Science And Technology,QingDao \\ E-mail:727116182@qq.com
}

\begin{abstract}
Keywords: energy feedback, common dc bus,super capacitor energy storage,grid-connected inverter.

Abstract.With the increase of demand for energy, energy recycling is becoming a hot spot in recent studies.The problem of motor feedback braking energy feedback system in energy fluctuation was proposed,the system is based on the combination of the super capacitor energy storage.the super capacitor can feed common dc bus energy feedback system, to improve the quality and efficiency of regenerative energy.This system adopt centralized rectifier technology to reduce energy consumption, motor work at two or four quadrant take braking, super capacitor energy storage system peak of regenerative energy recycling. When DC bus voltage in a certain value through inverter to grid-connected inverter,which can achieve the purpose of energy feedback. Through the Simulink module of MATLAB to simulation verification.
\end{abstract}

\section{Introduction}

With the increase of energy consumption, energy issues become the social development in the new century outstanding problems, then how to improve the energy efficiency become the research hot issues.Wang Wanxin [1] make research on how to use common dc bus to recycle multi-motor braking energy in paper making industry, and the application of rectifier/inverter feedback unit is to make energy feedback. Meanwhile, he make design to power grid. Literature[4] is the motor braking energy came up with converter circuit based on battery energy storage. Using battery as intermediate energy storage equipment to recycle the braking energy produced by motor, however, battery don't have the characteristics of instantaneous change quickly,and this characteristic make an influence on peak energy absorbed quickly.

Through the motor common dc bus and the battery energy storage converter research, designing the control system based on super capacitor energy storage and multi-motor common dc bus , and carries on the simulation verification.

\section{Multi-Motor Common DC Bus Energy Feedback System Structure}

Multi-motor common dc bus system usually consists of common dc bus, rectifier/feedback unit, inverter, etc[3].This article system basic structure increased the super capacitor energy storage unit, The system structure diagram, as is shown in Fig1.

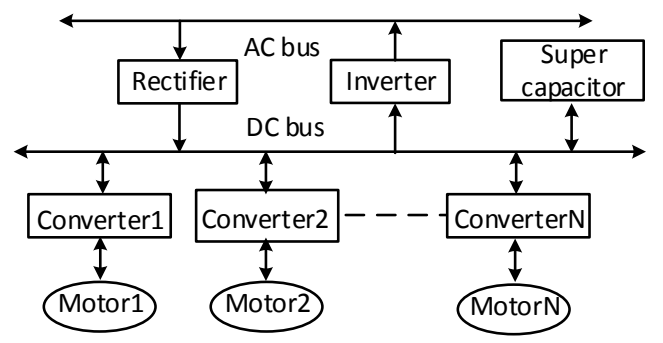

Fig1. Multi-motor common dc bus system structure

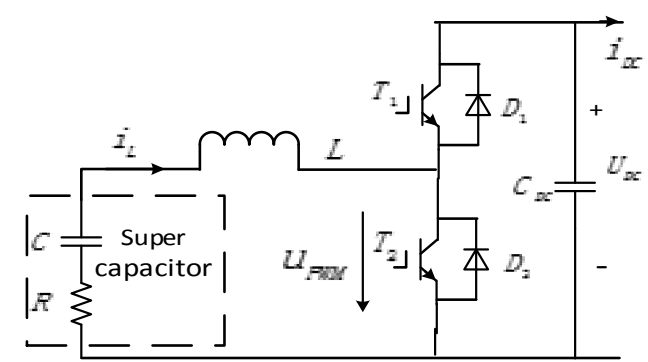

Fig2.Energy storage circuit model

With concentrated rectification technology, through the dc bus to provide multiple motor with power,it will again saving $8 \% \sim 15 \%$ on the basis of the traditional communication system 
energy.Motor braking energy peak is recycled to energy storage capacitor, then the energy produced by energy storage capacitor feedback to inverter. This method can diminish the interconnection device voltage surge and protect circuit,improving the quality of feedback electricity grid.

\section{The Feedback Energy Storage Grip System}

The Two-way DC - DC Energy Storage Circuit. With super capacitor modules to absorb the motor brake peak power, the motor in the second quadrant or four quadrant braking, the braking energy feedback to the common dc bus, when DC bus voltage reaches a certain peak value, super capacitor charging, the energy stored in the energy storage equipment.As the peak voltage is reduced, the super capacitor stored energy began to release, through the inverter to feedback braking energy to the power grid. As is shown in Fig2.A range of DC bus voltage $U_{D C 1}<U_{D C}<U_{D C 2}$.

(1)when $U_{D C}<U_{D C}$, energy storage circuit work in boosting mode, the super capacitor release energy to the dc bus, $T_{1}$ turn off, $T_{2}$ compared to a certain conduction, super capacitor $C$ by the fly-wheel diode $D_{1}$ to release energy to the dc bus .as is shown in Fig3.

(2)when $U_{D C}>U_{D C}$,energy storage circuit work in step-down Buck mode, the super capacitor $C$ absorb the dc bus spare energy, $T_{2}$ turn off, $T_{1}$ compared to a certain conduction, super capacitor by fly-wheel diode $D_{2}$ to absorb the energy of the dc bus.as is shown in Fig4.

(3)At the time $U_{D C 1}<U_{D C}<U_{D C 2}, T_{1}$ and $T_{2}$ are all open, DC-DC energy storage circuit does not work, energy by inverter circuit feedback power to the grid.

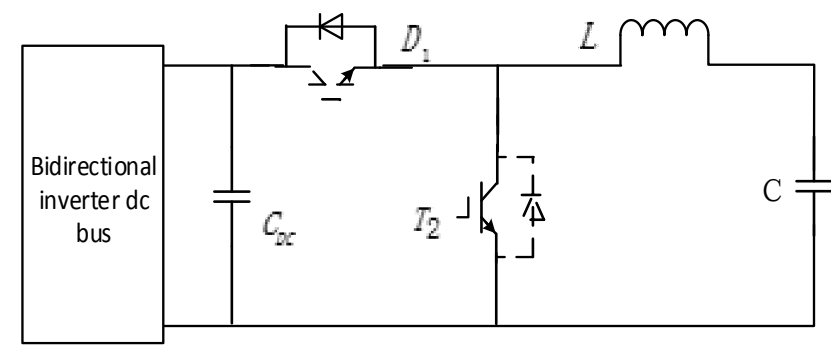

Fig3. Boost Model

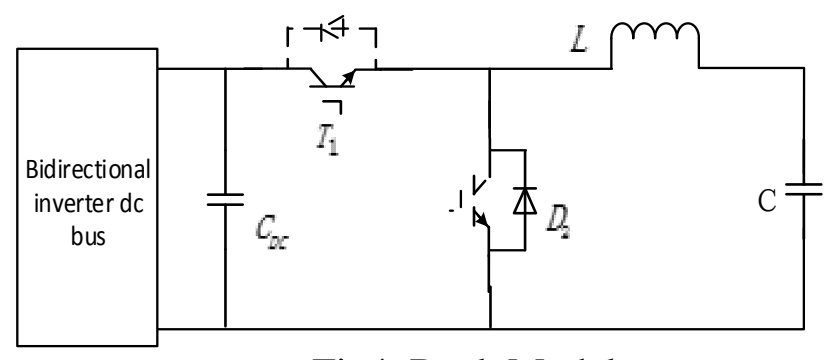

Fig4. Buck Model

Energy Feedback Inverter Grid Systems.Grid-connected inverter in the motor brake type dc side is voltage source, the control system of inverter output can be divided into the voltage control and current control.This inverter system uses the voltage control, through the PLL phase-locked control technology applied voltage and phase to adjust the size of power,making the grid feedback voltage source and the grid voltage source at the same phase and frequency, in order to prevent the harmonics of power grids, influence power quality of grid, The grid inverter circuit diagram, as shown in Fig5.

Inverter adopts two level of space vector PWM(SVPWM) control method [5-6], the method is $15.47 \%$ higher than traditional SPWM dc voltage utilization, less output harmonic, the advantages of small switch loss, and easy to carry out digital.

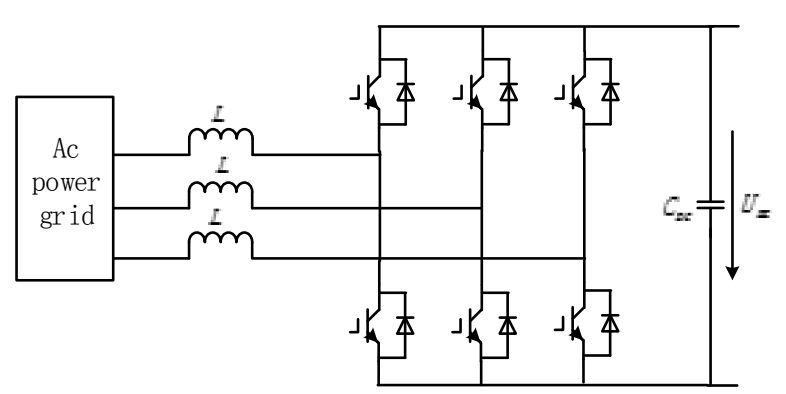

Fig5. Grid inverter circuit structure

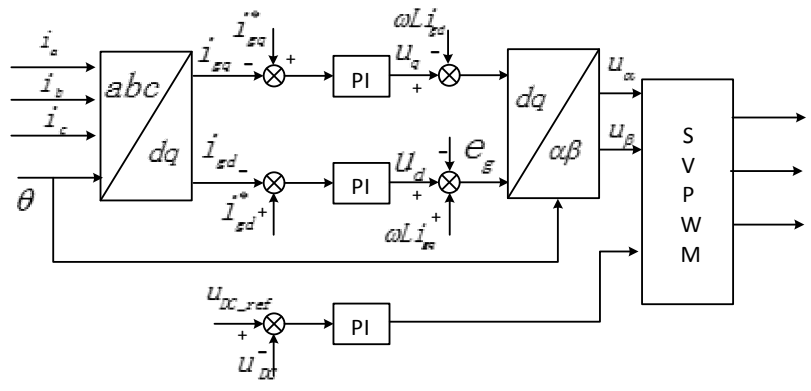

Fig6. Inverter control block diagram 


\section{Storage Feedback Grid System Control Method}

Grid Inverter Control Methods. for example.Grid converter is often uses the grid voltage oriented vector control strategy, the grid voltage vector direction as the $d$ axis direction, the network side converter mathematical model turn from three phase static coordinate transformation to the two-phase synchronous rotating coordinate system, so as to simplify the control.

By literature [7] can get formula (1)

$$
\left\{\begin{array}{c}
L \frac{d i_{g d}}{d t}=-R i_{g d}+\omega L i_{g q}+u_{d}-e_{g} \\
L \frac{d i_{g q}}{d t}=-R i_{g q}-\omega L i_{g d}+u_{q}
\end{array}\right.
$$

$$
\text { Make }\left\{\begin{array}{l}
u_{d}^{\prime}=L \frac{d i_{g d}}{d t}+R i_{g d} \\
u_{q}^{\prime}=L \frac{d i_{g q}}{d t}+R i_{g q}
\end{array}\right.
$$

The type (1) can be rewritten as $\quad\left\{\begin{array}{c}u_{d}^{\prime}=\omega L i_{g q}+u_{d}-e_{g} \\ u_{q}^{\prime}=-\omega L i_{g d}+u_{q}\end{array}\right.$

$u_{d}, u_{q}$ respectively as shaft current loop PI controller output value, by type (3) it can be seen that if the introduction of state feedback $-\omega L i_{g d} 、 \omega L i_{g q}$, and at the same time, the introduction of power grid voltage feed-forward compensation amount $-e_{g}$, then to realize $d q$ axial current component decoupling control, and input $\dot{u}_{d} 、 \dot{u}_{q}^{\prime}$ after a coordinate transformation to SVPWM modulation module, test dc bus voltage $u_{D C}$ at the same time, after $u_{D C}$ compared with $u_{D C_{-} r e f 1}$ through PI controller input to SVPWM module, which can generate the corresponding control pulse. Comprehensive the above analysis, according to the power grid voltage oriented vector control block diagram, the net side inverter is shown in Fig6.

DC - DC Converter Control Method.The main goal of DC - DC transform circuit in the system's is through the super capacitor charge and discharge control, eliminate the motor brake of peak power influence to power grid, and make the DC bus voltage to maintain in a certain range.This article uses the voltage and current double closed-loop control strategy to control DC - DC transform circuit,as is

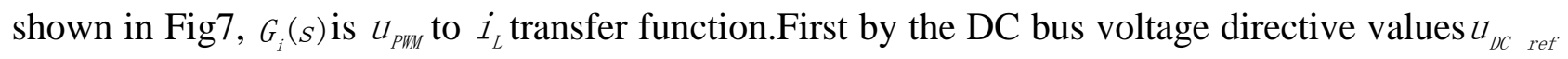
and its values $u_{D C}$ are compared, the deviation after PI regulation to form the energy storage inductor current instruction value $i_{L_{-} \text {ref }}$, and then $i_{L_{-} \text {ref }}$ compared with energy storage inductor current values $i_{L}$, both deviation after PI regulation form the PWM wave, then produce control after a triangular carrier PWM modulation converter switch tube conduction of trigger pulse, and help to get DC - DC converter output voltage, and then follow their instructions change control DC bus voltage.

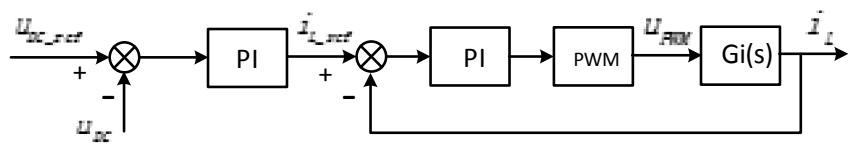

Fig7. DC - DC control block diagram

\section{System Simulation Research.}

In order to verify the feasibility of this system, with the aid of MATLAB simulation tool Simulink platform built the simulation model of motor brake,grid inverter and super capacitor.

(1)As is shown in Fig8(a)(b),which is the change of a single motor braking torque and speed.Can be seen from the simulation figure that when the system reach a certain number of the brake motor, which will generate feedback power peak that relatively large impact on system, and then needing to control the super capacitor to absorb power peak.

(2)As is shown in Fig9, which is the voltage curve, when capacitor module absorb power fluctuations.Can be seen from the diagram,super capacitor voltage should be equal after the motor braking power peak. 
(3)As is shown in Fig10,which is the energy feedback interconnection line voltage and line current waveform. When Electric energy feedback,the grid voltage remain, and current increase.

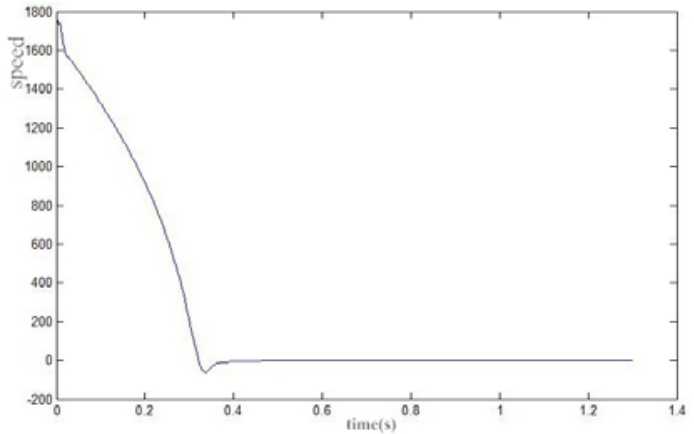

Fig8(a).Motor brake speed waveform

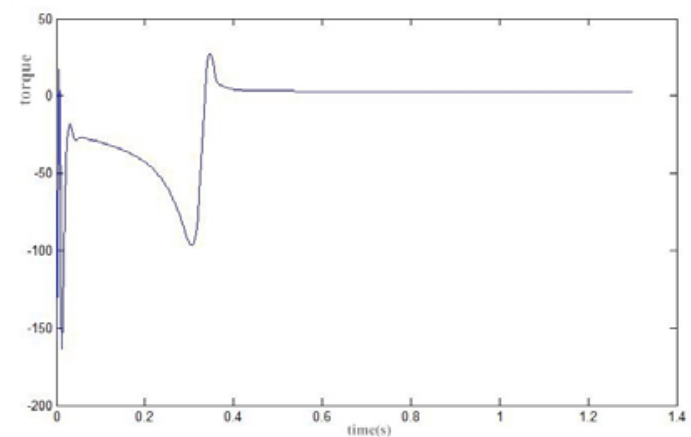

Fig8(b).Electric mechanism regulated torque

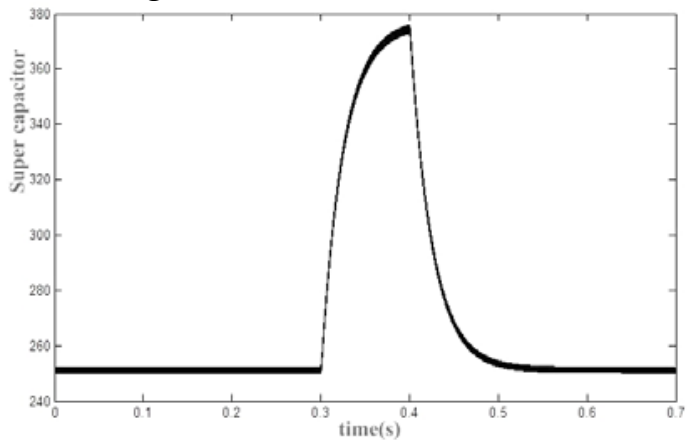

Fig9.The super capacitor voltage

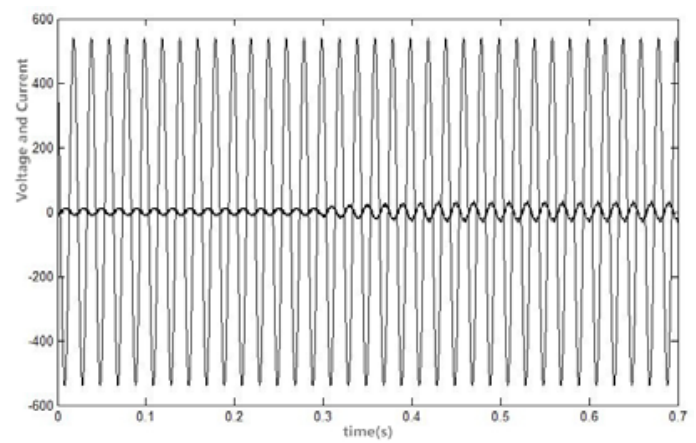

Fig10. Inverter and line voltage and current

\section{Conclusion}

Based on motor system braking energy recycling, on the dc bus parallel super capacitor energy storage unit, realizes the energy recovery system grid inverter each working cycle of constant power operation, effectively reduce the grid power fluctuation, improve the quality of the power grid, reduce the converter power rating, the final simulation results confirmed the stability of this system.

\section{References}

[1].Wanxin Wang. Application of Common-DC-bus in AC Drives[J].DianQi ChuanDong,2002-5.

[2]Yi Ruan,Boshi Chen.Control Systems of Electric Drives-Motion Control Systems[M].CHINA MACHINE PRESS,2013.In Chinese

[3].Jing-wen Chen.Application of common DC BUS technology in paper machine's driving system[J].China Pulp \& Paper Industry,Jan. 2009 Vol.30, No.2.In Chinese

[4]LI Ning-ning,Ling Shuang.etc.Research on battery DC/DC bidirectional converter using LCL filter[J]. Electric Machines and Control,2015,July,19(7).In Chinese

[5]WANG Ying-Jun.,YANG Yan-hang,MA Bao-hui. Research on simulation of the voltage space vector PWM[J].ELECTRIC DRIVE AUTOMATION, 2011, 33.In Chinese

[6]Ll Hong-mei,Ll Zhong-jie,DU Shi-jun. Dynamic Performance simulation of SVPWM Inverter fed induction motor[J].Electric Machines and Control, 2001, Sept, 5(3).In Chinese

[7]Wei-zhong Ding.Research on Direct Power Control and Communication Function of Direct-drive PMSG WECS[D].Zhejiang University,2015.1.22. 